\title{
Nutritional Status of Adolescents in Semi-urban Community in Dukuchhap Village of Lalitpur, Nepal
}

\author{
Paudel S, ${ }^{1 *}$ Limbu NPM, ${ }^{2}$ Pradhan $\mathrm{PMS}^{3}$ Shrestha $\mathrm{SM}^{3}$, Shah $\mathrm{AK},{ }^{4}$ Daha $\mathrm{SK}^{4}$, Baral KP
}

\section{Affiliation}

1. Assistant Professor, Department of Community Health Sciences, Patan Academy of Health Sciences, Lalitpur, Nepal

2. Lecturer, Department of Community Health Sciences, Patan Academy of Health Sciences, Lalitpur, Nepal

3. Assistant Professor, Department of Community Medicine and Public Health, Maharajgunj Medical Campus, Institute of Medicine, Tribhuvan University, Nepal

4. MBBS $3^{\text {td }}$ Year Student, Patan Academy of Health Sciences, Lalitpur, Nepal

5. Professor, Department of Community Health Sciences Patan Academy of Health Sciences, Lalitpur, Nepal

\section{ARTICLE INFO}

\section{Article History}

Received : 5 March, 2017

Accepted : 10 April, 2017

Published : 30 April, 2017

(C) Authors retain copyright and grant the journal right of first publication with the work simultaneously licensed under Creative Commons Attribution License CC - BY 4.0 that allows others to share the work with an acknowledgment of the work's authorship and initial publication in this journal.

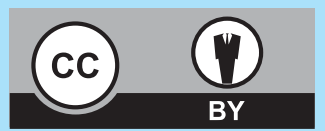

ORA 17

\section{* Corresponding Author}

Mr. Sudarshan Paudel Assistant Professor

Department of Community Health Sciences (DCHS) Patan Academy of Health Sciences (PAHS), Lalitpur, Nepal Email: sudarshanpaudel@pahs.edu.np

\section{Citation}

Paudel S, Limbu NPM, Pradhan PMS, Shrestha SM, Shah AK, Daha SK, Baral KP P. Nutritional Status of Adolescents in Semi-urban Community in Dukuchhap Village of Lalitpur, Nepal. BJHS 2017; 2 (1) 2:110-116.

\section{ABSTRACT}

\section{Introduction}

Many Nepali adolescents (10-19 years) are undernourished, which increases the risk of morbidity and mortality. Inadequate nutrition during adolescence can retard physical growth and sexual maturation and increases the risk of adult lifestyle diseases. There is a dearth of research on the socio-demographic factors associated with the nutritional status of adolescents in Nepal.

\section{Objective}

To assess the nutritional status of adolescents (10-19 years) in Dukuchhap Viillage of Lalitpur, Nepal

\section{Methodology}

A community based descriptive cross-sectional study was carried out by medical students during their field placement for community diagnosis in Dukuchhap Village of Lalitpur from $22^{\text {nd }}$ November- $19^{\text {th }}$ December 2017. All 10-19 years adolescent population was included in the study. Among the total population (2545) study, 474 were adolescent. The data were collected using semi-structured questionnaire. Physical and anthropometric measurement were done. Data were analyzed using of WHO Z-scores criteria and cut offs points. All the findings were compared with Nepal Demographic and Health Survey, 2011 and other researches published in different journals on related topic. Excel version 2010 and SPSS version 13.0 were used to enter and analyze data.

\section{Results}

The prevalence of stunting was found out to be $36.28 \%$.More males $(16.51 \%)$ than females $(12.60 \%)$ were severely stunted and $21.70 \%$ of male and $22.14 \%$ of female were moderately stunted. Among total respondents, $14.4 \%$ were severely stunted and $21.9 \%$ were moderately stunted. More numbers of male (38.2\%) were stunted than female (34.7\%).

\section{Conclusion}

Prevalence of malnutrition among adolescent was more in 1012 years age group. The prevalence of moderate stunting was slightly high in females than males. Adolescents with extended family type, increasing number of family members \& agriculture, labourer and local business as main family occupation are more prone to suffer from malnutrition.

\section{KEY WORDS}

Adolescent, malnutrition, stunting, semi-urban, Nepal 


\section{INTRODUCTION}

World Health Organization (WHO) defines adolescence as the age group between 10 and 19 years ${ }^{1}$. Inadequate nutrition during adolescence can retard growth and sexual maturation, and increase the risk of adult lifestyle diseases. The prevalence of malnutrition among adolescents is high in developing countries. ${ }^{2}$

Little less research has been done on adolescent nutritional status in Nepal. Though Indian studies are not directly applicable to Nepali populations, some comparisons might be useful. A study in Karnataka state of India of the 13-19 age group revealed that in rural areas more than one-third (36\%) of boys and nearly a half (45.2\%) of girls were stunted, while in urban areas about one-fourth $(21.7 \%)$ of boys and girls (26.5\%) were stunted. ${ }^{3}$ The same study found that nearly half (48.4\% in rural and $43.5 \%$ in urban) of adolescent boys and one fifth (19.4\% in rural and $21.1 \%$ in urban) of adolescent girls were energy deficient, but only a very few ( $2.3 \%$ of rural and $5.4 \%$ of urban girl) were considered chronically energy deficient, however, the percentage were little higher (18.8\% in rural and $17.4 \%$ in urban boys) in case of boys. Energy deficient refers to the BMI for-age Z-score below -2SD i.e., the energy requirement is not sufficient. A study on Nutritional Status of Adolescent Girls from an Urban Slum Area in South India concluded that there is a high prevalence of stunting (47\%), of underweight (42.6\%) and of thinness (20.6\%) among adolescent girls in this slum community. ${ }^{4}$

The study aimed to assess the demographic and health status focusing on nutritional status of the VDC and also to evaluate health resources, services, and systems of care. The specific objectives of the study were: assess nutritional status of adolescents; analyze the distribution of weight-forage, height-for-age between ethnic groups, and estimate the prevalence of malnutrition in each group.

\section{METHODOLOGY}

From $22^{\text {nd }}$ November to $19^{\text {th }}$ December, 2015, medical students studying in third year in the Patan Academy of Health Sciences (PAHS), Nepal conducted a survey in Dukuchhap village as a field based curricular activities. The Community Health Sciences (CHS) department oriented 61 medical students about elements of 'Community Diagnosis Survey' focusing on correct use of anthropometric measurements, assessing vital signs and conducting questionnaire. The department played lead roll to develop research protocols and it was approved from academic council of PAHS. The study was thoroughly supervised by eight CHS faculties.

The place of the study was chosen to be Dukuchhap Village Developmental Committee (VDC) which is located $12 \mathrm{KM}$ southeast from the capital city (Kathmandu) of Nepal. According to the national census $2011^{5}$, the VDC had area of 4.96 square kilometer $\left(\mathrm{km}^{2}\right)$ while the total population was 2,669 with high density, 537 inhabitants per square kilometer $\left(\mathrm{Inh} / \mathrm{km}^{2}\right)$. It has been declared (along with other two VDCs) as urban area (Karyavinayak Municipality) by government of Nepal in 2015.

The students conducting the survey first compiled household lists. The students visited each and every houses, obtained consent in writing from the household head to serve as respondent. A maximum of three visits were made to each house. Anthropometric measurements of all individuals were recorded. Weight was measured to the nearest $0.1 \mathrm{Kg}$ using a digital weighing scale, which was placed on a horizontal plane surface to minimize the error. Height was measured to the nearest $1 \mathrm{~cm}$. using a portable stick fitted with measuring tape. WHO Z-scores ${ }^{1}$ criteria and cut offs points were used to estimate the prevalence of underweight, thinness, stunting and wasting and of different grades of malnutrition amongst adolescents based on gender and different ethnic groups were calculated. All the findings were compared with standard data from Nepal Demographic and Health Survey 2011. ${ }^{6}$ Excel version 2010 and SPSS version 13.0 were used to enter and analyze data.

\section{RESULTS}

Among 2545 studied population of Dukuchhap village of Lalitpur district in Nepal, $18.6 \%$ of them were adolescents. Out of the adolescents, $55.3 \%$ of them were females and $44.7 \%$ of them were males. The total number of female and male adolescents of different age group is shown in Table 1.

Table 1: Age and gender wise distribution of adolescents at Dukuchhap, Lalitpur

\begin{tabular}{|cccc|}
\hline Age (Years) & Female & Male & Total \\
\hline 10 & 27 & 23 & 50 \\
\hline 11 & 21 & 25 & 46 \\
\hline 12 & 34 & 26 & 60 \\
\hline 13 & 17 & 24 & 41 \\
\hline 14 & 29 & 24 & 53 \\
\hline 15 & 20 & 12 & 32 \\
\hline 16 & 27 & 16 & 43 \\
\hline 17 & 28 & 22 & 50 \\
\hline 18 & 28 & 30 & 58 \\
\hline 19 & 31 & 10 & 41 \\
\hline Total & 262 & 212 & 474 \\
\hline
\end{tabular}




\section{Weight, Height and BMI of girls and boys of various ethnic groups}

The main ethnic group was Danuwar, consisting $31.0 \%$ of the total adolescent population and the other ethnic groups were Tamang (30.4\%), Chhetri (28.3\%), Brahmin (4.4\%), Newar (4.4\%) and others i.e. Dalit, Magar and Limbu.

Brahmin girls' mean weight, mean height and average body mass index was the highest among all ethnic groups of girls studied with $47.1 \mathrm{~kg}$ (SD \pm 7.7$), 151.9 \mathrm{~cm}(\mathrm{SD} \pm 5.2)$ and 22.8 $\mathrm{kg} / \mathrm{m}^{2}$ respectively. Similarly, the lowest mean weight was
$39.3 \mathrm{~kg}(\mathrm{SD} \pm 8.8)$ of Chhetri girls, the lowest mean height was $142.9 \mathrm{~cm}(\mathrm{SD} \pm 17.6)$ of Newari girls and lowest BMI was 18.2 $\mathrm{kg} / \mathrm{m}^{2}$ of Chhetri girls.

Similarly, Chhetris boys' have the highest mean weight and mean height among all ethnic boys studied with $44.7 \mathrm{~kg}$ $(S D \pm 12.1)$ and $152.3 \mathrm{~cm}(S D \pm 15.9)$ respectively but their BMI was the second highest with $18.9 \mathrm{~kg} / \mathrm{m}^{2}$. Similarly, both the lowest mean weight and height was $32.3 \mathrm{~kg}(\mathrm{SD} \pm 7.89)$ and $132.6 \mathrm{~cm}(\mathrm{SD} \pm 12.6)$ of Newari boys, however, the lowest BMI was $17.7 \mathrm{~kg} / \mathrm{m} 2$ of Danuwar boys.

Table 2: Mean weight, height and BMI according to ethnicity

\begin{tabular}{|c|c|c|c|c|c|c|}
\hline \multicolumn{7}{|c|}{ Ethnic groups } \\
\hline Parameters & $\begin{array}{l}\text { Danuwar } \\
(n=147)\end{array}$ & $\begin{array}{l}\text { Tamang } \\
(n=144)\end{array}$ & $\begin{array}{l}\text { Chhetri } \\
(n=133)\end{array}$ & $\begin{array}{l}\text { Brahmin } \\
(n=21)\end{array}$ & $\begin{array}{l}\text { Newar } \\
(n=21)\end{array}$ & $\begin{array}{l}\text { Others } \\
(n=8)\end{array}$ \\
\hline $\begin{array}{l}\text { Girls weight in Kg } \\
\text { (Mean } \pm \text { SD) }\end{array}$ & $\begin{array}{l}40.00 \pm 9.84 \\
(n=80)\end{array}$ & $\begin{array}{l}40.53 \pm 10.28 \\
(n=82)\end{array}$ & $\begin{array}{l}39.26 \pm 8.79 \\
(n=72)\end{array}$ & $\begin{array}{l}47.06 \pm 7.71 \\
(n=12)\end{array}$ & $\begin{array}{l}39.88 \pm 11.35 \\
(n=13)\end{array}$ & $\begin{array}{l}46.37 \pm 6.5 \\
(n=3)\end{array}$ \\
\hline $\begin{array}{l}\text { Girls Height in } \mathrm{cm} \\
\text { (Mean } \pm \text { SD) }\end{array}$ & $145.40 \pm 10.03$ & $143.17 \pm 11.20$ & $145.81 \pm 9.35$ & $151.92 \pm 5.20$ & $142.92 \pm 17.60$ & $147 \pm 5$ \\
\hline$B M I\left(k g / m^{2}\right)$ & 18.67 & 19.48 & 18.22 & 22.83 & 19.24 & 21.44 \\
\hline $\begin{array}{l}\text { Boys weight in } \mathrm{Kg} \\
\text { (Mean } \pm \text { SD) }\end{array}$ & $\begin{array}{l}38.29 \pm 12.28 \\
(n=67)\end{array}$ & $\begin{array}{l}42.40 \pm 13.31 \\
(n=62)\end{array}$ & $\begin{array}{l}44.73 \pm 12.08 \\
(n=61)\end{array}$ & $\begin{array}{l}37.86 \pm 11.36 \\
(n=9)\end{array}$ & $\begin{array}{l}32.32 \pm 7.89 \\
(n=8)\end{array}$ & $\begin{array}{l}43.36 \pm 14.3 \\
(n=5)\end{array}$ \\
\hline $\begin{array}{l}\text { Boys Height in } \mathrm{cm} \\
\text { (Mean } \pm \text { SD) }\end{array}$ & $145.21 \pm 14.88$ & $148.90 \pm 17.40$ & $152.26 \pm 15.93$ & $144.22 \pm 13.49$ & $132.63 \pm 12.56$ & $147 \pm 20.8$ \\
\hline$B M I\left(\mathrm{~kg} / \mathrm{m}^{2}\right)$ & 17.67 & 18.78 & 18.93 & 17.91 & 18.38 & 19.52 \\
\hline
\end{tabular}

\section{Prevalence of underweight}

Out of 474 adolescents, $2.1 \%$ of them were found to be underweight. However, the prevalence of underweight was slightly more in male $(2.4 \%)$ than in female (1.9\%). There was

Table 3: Shows the prevalence of underweight not any single case of severely underweight adolescent. The prevalence of underweight was highest among age group 14 (7.4\%), followed by age group 12 (6.3\%) and 19 (3.3\%) respectively in female. In male, the prevalence was highest among age group 16 (14.3\%), followed by age group 18 (7.1\%) and 14 (4.4\%).

\begin{tabular}{|c|c|c|c|c|c|c|}
\hline \multirow[t]{2}{*}{ Age (years) } & \multicolumn{3}{|c|}{ Girls (N=262) } & \multicolumn{3}{|c|}{ Boys (N=212) } \\
\hline & $\begin{array}{l}\leq-2 Z \\
\text { score }\end{array}$ & $\begin{array}{l}-2 \text { to }-3 \mathrm{Z} \\
\text { score }\end{array}$ & $\begin{array}{l}>-3 Z \\
\text { score }\end{array}$ & $\begin{array}{l}\leq-2 Z \\
\text { score }\end{array}$ & $\begin{array}{c}-2 \text { to }-3 \mathrm{Z} \\
\text { score }\end{array}$ & $\begin{array}{l}\geq-3 \mathrm{Z} \\
\text { score }\end{array}$ \\
\hline 10 & 27 & 0 & 0 & 23 & 0 & 0 \\
\hline 11 & 21 & 0 & 0 & 25 & 0 & 0 \\
\hline 12 & 32 & 20 & 2 & 6 & 0 & 0 \\
\hline 13 & 17 & 0 & 0 & 24 & 0 & 0 \\
\hline 14 & 27 & 20 & 2 & 3 & 1 & 0 \\
\hline 15 & 20 & 0 & 0 & 12 & 0 & 0 \\
\hline 16 & 27 & 0 & 0 & 14 & 2 & 0 \\
\hline 17 & 28 & 0 & 0 & 22 & 0 & 0 \\
\hline 18 & 28 & 0 & 0 & 28 & 2 & 0 \\
\hline 19 & 30 & 1 & 0 & 10 & 0 & 0 \\
\hline
\end{tabular}

Note: $\leqq-2 Z$ score $=$ Normal, -2 to $-3 Z$ score $=$ Moderate, $\geq-3 Z$ score $=$ severely Underweight 


\section{Prevalence of Stunting}

Out of 474 adolescents, $14.4 \%$ of them were severely stunted and $21.9 \%$ of them were moderately stunted. However, the prevalence of stunting was slightly more in male (38.2\%) than slightly more in females (22.1\%) than males (21.7\%) but the prevalence of severe stunting was more in males (16.5\%) in female (34.7\%). The prevalence of moderate stunting was than females (12.6\%). (Table 4)

\section{Table 4: Prevalence of Stunting by Age and Gender}

\begin{tabular}{|c|c|c|c|c|c|c|}
\hline \multirow[t]{2}{*}{ Age (years) } & \multicolumn{3}{|c|}{ Girls (N=262) } & \multicolumn{3}{|c|}{ Boys (N=212) } \\
\hline & $\begin{array}{l}\leq-2 \mathrm{Z} \\
\text { score }\end{array}$ & $\begin{array}{c}-2 \text { to }-3 \mathrm{Z} \\
\text { score }\end{array}$ & $\begin{array}{l}>-3 Z \\
\text { score }\end{array}$ & $\begin{array}{l}\leq-2 \mathrm{Z} \\
\text { score }\end{array}$ & $\begin{array}{c}-2 \text { to }-3 \mathrm{Z} \\
\text { score }\end{array}$ & $\begin{array}{l}\geq-3 Z \\
\text { score }\end{array}$ \\
\hline 10 & 16 & 8 & 3 & 14 & 4 & 5 \\
\hline 11 & 13 & 2 & 6 & 16 & 7 & 2 \\
\hline 12 & 27 & 4 & 3 & 17 & 5 & 4 \\
\hline 13 & 10 & 6 & 1 & 13 & 5 & 6 \\
\hline 14 & 20 & 5 & 4 & 18 & 2 & 4 \\
\hline 15 & 12 & 6 & 2 & 8 & 2 & 2 \\
\hline 16 & 21 & 4 & 2 & 8 & 5 & 3 \\
\hline 17 & 17 & 6 & 5 & 16 & 4 & 2 \\
\hline 18 & 21 & 4 & 3 & 18 & 7 & 5 \\
\hline 19 & 14 & 13 & 4 & 3 & 5 & 2 \\
\hline Total & 171 & 58 & 33 & 131 & 46 & 35 \\
\hline
\end{tabular}

Note: $\leqq-2 Z$ score $=$ Normal, -2 to $-3 Z$ score $=$ Moderate,$\geq-3 Z$ score $=$ severely Underweight

\section{Prevalence of stunting by age}

The prevalence of stunting was more among age group 19 (54.8\%), followed by age groups 13 (41.2\%), 10 (40.7\%), 15 $(40 \%)$ and $17(39.3 \%)$ respectively in female. Also in male, the prevalence of stunting was more among age group 19 (70\%), $16(50 \%), 13(45.8 \%), 18(40 \%)$ and 10 (39.1\%). Similarly, the prevalence of stunting was least in age group $12(20 \%)$ in female and $14(25 \%)$ in male respectively. (Table 5)

\section{Table 5: Prevalence of Stunting by Age}

\begin{tabular}{|lcccccl} 
Age & Female & Stunted & $\%$ & Male & Stunted & $\%$ \\
\hline 10 & 27 & 11 & 40.7 & 23 & 9 & 39.1 \\
\hline 11 & 21 & 8 & 38.1 & 25 & 9 & 36 \\
\hline 12 & 34 & 7 & 20.6 & 26 & 9 & 34.6 \\
\hline 13 & 17 & 7 & 41.2 & 24 & 11 & 45.8 \\
\hline 14 & 29 & 9 & 31.0 & 24 & 6 & 25 \\
\hline 15 & 20 & 8 & 40 & 12 & 4 & 33.3 \\
\hline 16 & 27 & 6 & 22.2 & 16 & 8 & 50 \\
\hline 17 & 28 & 11 & 39.3 & 22 & 6 & 27.3 \\
\hline 18 & 28 & 7 & 25 & 30 & 12 & 40 \\
\hline 19 & 31 & 17 & 54.8 & 10 & 7 & 70 \\
\hline Total & 262 & 91 & 34.7 & 212 & 81 & 38.2 \\
\hline
\end{tabular}

\section{Prevalence of malnutrition among different age groups}

In the adolescent population (Table 6), $21.9 \%$ were severely thin (BMI < 16), 9.3\% moderately thin (BMI $16-<17$ ) and $17.3 \%$ were mildly thin (BMI $17-<18.5$ ). A total of $48.5 \%$ were suffering from malnutrition, mostly in the 10-12 age group (56.5\%), followed by age group 13-15 (27.8\%) and then $16-19$ (7.6\%). A total of $26.6 \%$ were suffering from moderate and mild malnutrition. Moderate plus mild malnourishment was also more prevalent in the age group $10-12$ (42.9\%) followed by age group $13-15$ (31.8\%) and then $16-19$ (25.4\%).

\section{Prevalence of malnutrition by main family occupation}

Of the 474 adolescents (Table 6), 236 (49.8\%) families were engaged in agriculture, 25 (5.3\%) in business, 82 (17.3\%) in service works, 67 (14.1\%) were laborers, and 64 had "other" occupations. Among adolescents whose families stated agriculture as main family occupation, $22.9 \%$ were severely malnourished, $8.9 \%$ moderately, and $18.2 \%$ mildly malnourished. Among adolescents with local business as the main family occupation $24 \%$ were severely malnourished, $8 \%$ moderately, $16 \%$ mildly malnourished. Among adolescents with service as their main family occupation, $14.6 \%$ were severely malnourished, $8.5 \%$ moderately and $18.3 \%$ mildly malnourished. Among adolescents with laborer as their main family education, $28.4 \%$ were severely 
malnourished, $11.9 \%$ moderately and $14.9 \%$ mildly malnourished. Of adolescents with other main family occupations, $20.3 \%$ were severely malnourished, $9.4 \%$ moderately, and $15.6 \%$ mildly malnourished.

\section{Prevalence of malnutrition by family type}

Of the total of 474 adolescents (Table 6), 260 (54.85\%) had a nuclear family and 214 (45.15\%) had joint/extended family type. Among adolescents belonging to nuclear family, $21.5 \%$ were severely malnourished, $10.4 \%$ moderately and $19.2 \%$ were mildly malnourished. Among the adolescents belonging to joint families, $22.4 \%$ were severely malnourished, $7.9 \%$ moderately, $15.0 \%$ mildly malnourished.

\section{Prevalence of malnutrition by Family size}

Among the 474 adolescents (Table 6), 35.2\% had $\leq 4$ family members, $51.9 \%$ had 5-7 family members, $1 \%$ had $8-10$ family members and $1.4 \%$ had $\geq 11$ family members. Among those with $\leq 4$ family members, $20.4 \%$ were severely malnourished, $8.4 \%$ were moderately and $17.4 \%$ were mildly malnourished. Among those with 5-7 family members, 23.2\% were severely malnourished, $10.2 \%$ were moderately and $17.5 \%$ were mildly malnourished. Among those with 8-10 family members, $19.6 \%$ were severely, $7.1 \%$ were moderately and $16.1 \%$ were mild malnourished. Among $\geq 11$ members as family size, $40 \%$ were severely malnourished, $20 \%$ were moderately and $20 \%$ were mildly malnourished.

Among the 474 adolescents, 13 (2.74\%) of them had BMI more than normal range. Among those 13, 5 (38.46\%) female and 8 (61.54\%) of male were overweight/Obese.

Table 6: Prevalence and socio-demographic correlates of BMI amongst adolescents

Table 6: Prevalence and socio-demographic correlates of BMI amongst adolescents

\begin{tabular}{|c|c|c|c|c|c|c|c|c|c|c|c|}
\hline \multirow{3}{*}{ Parameters } & \multirow{3}{*}{$\mathbf{N}$} & \multicolumn{2}{|c|}{$<16$} & \multicolumn{2}{|c|}{$16-<17$} & \multicolumn{2}{|c|}{$17-<18.5$} & \multicolumn{2}{|c|}{$18.5-<25$} & \multicolumn{2}{|c|}{$=25$} \\
\hline & & $n$ & $\%$ & $n$ & $\%$ & $\mathbf{n}$ & $\%$ & 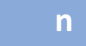 & $\%$ & $\mathbf{n}$ & $\%$ \\
\hline & & \multicolumn{2}{|c|}{ GR-3 Thinner } & \multicolumn{2}{|c|}{ GR-2 Thinner } & \multicolumn{2}{|c|}{ GR-1 Thinner } & \multicolumn{2}{|c|}{ Normal BMI } & \multicolumn{2}{|c|}{ Overweight Obese } \\
\hline \multicolumn{12}{|l|}{ Age (Years) } \\
\hline $10-12$ & 156 & 76 & 48.72 & 29 & 18.58 & 25 & 16.02 & 24 & 15.38 & 2 & 1.28 \\
\hline $13-15$ & 126 & 24 & 19.05 & 11 & 8.73 & 29 & 23.01 & 58 & 46.03 & 4 & 3.17 \\
\hline $16-19$ & 192 & 4 & 2.08 & 4 & 2.08 & 28 & 14.58 & 149 & 77.60 & 7 & 3.65 \\
\hline \multicolumn{12}{|c|}{ Main Family Occupation } \\
\hline Agriculture & 236 & 54 & 22.88 & 21 & 8.90 & 43 & 18.22 & 112 & 47.46 & 6 & 2.54 \\
\hline Business & 25 & 6 & 24 & 2 & 8 & 4 & 16 & 12 & 48 & 1 & 4 \\
\hline Service & 82 & 12 & 14.63 & 7 & 8.54 & 15 & 18.29 & 45 & 54.88 & 3 & 3.66 \\
\hline Laborer & 67 & 19 & 28.36 & 8 & 11.94 & 10 & 14.92 & 29 & 43.28 & 1 & 1.49 \\
\hline Other & 64 & 13 & 20.31 & 6 & 9.38 & 10 & 15.63 & 33 & 51.56 & 2 & 3.13 \\
\hline \multicolumn{12}{|l|}{ Types of Family } \\
\hline Nuclear & 260 & 56 & 21.54 & 27 & 10.38 & 50 & 19.23 & 120 & 46.15 & 7 & 2.69 \\
\hline Joint/extended & 214 & 48 & 22.43 & 17 & 7.94 & 32 & 14.95 & 111 & 51.86 & 6 & 2.80 \\
\hline \multicolumn{12}{|l|}{ Family Size } \\
\hline$\leq 4$ members & 167 & 34 & 20.36 & 14 & 8.38 & 29 & 17.37 & 87 & 52.09 & 3 & 1.80 \\
\hline 5 - 7 members & 246 & 57 & 23.17 & 25 & 10.16 & 43 & 17.48 & 113 & 45.93 & 8 & 3.25 \\
\hline 8 - 10 members & 56 & 11 & 19.64 & 4 & 7.14 & 9 & 16.07 & 30 & 53.57 & 2 & 3.57 \\
\hline$\geq 11$ members & 5 & 2 & 40 & 1 & 20 & 1 & 20 & 1 & 20 & & 0 \\
\hline
\end{tabular}

\section{DISCUSSION}

\section{Weight, Height and BMI of girls and boys of various ethnic groups}

Income, lifestyle, health, dominant position in society and many other factors vary widely between ethnic groups. So, we tried to assess the differences in nutritional status between ethnic groups. The five main castes in Dukuchhap were Danuwar, Tamang, Chhetri, Brahmin and Newar.
As per Body weight (Table 2), Chhetri girls were on the lowest average with $39.3 \mathrm{~kg}$ and had the lowest Body Mass Index with 18.2 falling in the thinness category whereas remaining other girls from different ethnicity all had normal BMI. However, Brahmin girls were on the highest average body weight with $47.1 \mathrm{~kg}$ and correspondingly the highest BMI among all other ethnic girls. Similarly for body weight of 
boys, Newar boys had the lowest average with $32.3 \mathrm{~kg}$ and unlike Chhetri girls, the Chhetri boys had the highest average body weight with $44.7 \mathrm{~kg}$.

Likewise when ethnic groups were compared on their heights Newar girls were of the shortest average stature with $142 \mathrm{~cm}$. In contrast, Brahmin girls were on the highest average body height with $151.9 \mathrm{~cm}$ and have the highest BMI with 22.8 $\mathrm{kg} / \mathrm{m} 2$ among all of them. Similarly for height of Boys, Newar boys do have the lowest average height with $132.6 \mathrm{~cm}$. The Newar, Danuwar and Brahmin boys fall under the thinness category but the Danuwar boys have the lowest BMI due to the wider dispersion both in body weight and height.

As per the body mass index, firstly, girls were better compared to their male counterparts except of the Chhetri girls which is opposite of what is expected of the community in Nepal where the society is predominantly dominated by male. Secondly, BMI of both Tamang girls and Tamang boys were better amongst all other ethnic group only because in Tamang community there is no discrimination between male child and female child, however, this ethnic group have the widest variability in their weight and height.

\section{Prevalence of underweight}

Out of 474 adolescents, 464 (97.9\%) of them were found to be in normal weight indicating that this community lies in food secure area in Nepal. However, the prevalence of underweight was slightly more in male $(2.4 \%)$ than in female (1.9\%). There was no case of severely underweight adolescent. However, $21.9 \%$ (104/474) of them were in chronic energy deficient condition with $\mathrm{BMI}<16$.

\section{Prevalence of Stunting}

The prevalence of stunting in the adolescent population was 172 (36.3\%) of whom girls were $52.90 \%$ and boys $47.1 \%$ respectively. The stunting percentage of boys was lowest $25 \%$ $(6 / 24)$ at age 14 which coincide with the growth spurt for boys. Similarly, in case of female the lowest stunting percentage was $21 \%$ (7/34) at age 12 which also coincide with the growth spurt for girls. The prevalence of stunting was found to be $36.28 \%$ and this is an improvement over similar studies in Nepal, where $47 \%$ stunting was reported in $1994^{8}$ While not comparable, a study done in Darjeeling district, India revealed stunting prevalence to be $46.6 \%{ }^{9}$. A 2005 study done in West Bengal, India revealed the prevalence of stunting to be $37.8 \% .{ }^{10}$ This shows the prevalence of stunting is decreasing in Nepal but it is still a great issue of concern to be solved.

A recent study of 2013 conducted in Chiro town, Ethiopia has revealed the prevalence of stunting was higher in early adolescence (7.8\%) than late adolescence (6.8\%), which is very lower than to our findings. ${ }^{11}$

\section{Prevalence of Malnutrition Main Family Occupation, Family type and family size}

Gender, types of residence, family size, family income, and ethnicity are all contributing factors in malnutrition. This study shows that there is a higher prevalence of malnutrition among adolescents whose families engage in agriculture, general labor, or local business as their main family occupation. This study also discloses the prevalence of malnutrition to be more in extended family type than in nuclear type and increased malnutrition prevalence with increase in family size. This finding is new to Nepal but a recent study in Iran found a similar association between larger family size and malnutrition. ${ }^{12}$ This supports our finding on effects of different demographic factors on nutritional status.

\section{CONCLUSION}

The prevalence of stunting was found to be $36.28 \%$ among the study population. Prevalence of stunting shows decreasing trend and was more prevalent in girls than in boys (52.90\% vs. $47.1 \%)$. Lower stunting percentage at 14 years in boys and in 12 years in girls coincides with the growth spurt for boys \& girls.

The prevalence of underweight was slightly more in male $(2.36 \%)$ than in female $(1.91 \%)$ and approximately twenty two percent of the adolescents were chronic energy deficient.

Adolescents of families having agriculture, laborer, and local business as their main family occupation are more prone to suffer from malnutrition. The prevalence of malnutrition is higher in extended families, and malnutrition increases in prevalence as the numbers of family member increases.

\section{ACKNOWLEDGEMENT}

We would like to acknowledge all Department of Community Health Sciences (DCHS) faculty members of Patan Academy of Health Sciences (PAHS) for their support to conceptualize this article. This study would not have been possible without support, time and participation of all families from Dukuchhap Village Development Committee in Lalitpur District. Our best appreciation goes to third batch medical students of Patan Academy of Health Sciences for their sincere effort to collect information visiting every household during their field posting.

\section{CONFLICT OF INTEREST}

We declare no conflict of interest. 


\section{REFERENCES}

1. WHO, Growth reference 5-19 years. 2007 WHO.

2. Centers for Disease Control and Prevention (CDC), Nutritional assessment of adolescent refugees Nepal, 1999. MMWR Morb Mortal Wkly Rep. 2000 Sep 29;49(38):8647.

3 T. Rajaretnam and Jyoti S. Hallad. Nutritional Status of Adolescents in Northern Karnataka, Vol. 58, No.1, June-2012

4. K. Prashant and ChandanShaw, The Indian Journal of Pediatrics, (Ministry of Health and Population, 2011)(Ministry of Health and Population, 2011)Nutritional Status of Adolescent Girls from an Urban Slum Area in South India ;May 2009

5. Village Development Committee and Demographic Profile of Nepal 2013. Mega Publication \& Research centre, Nepal

6. MoHP, Government of Nepal, Ministry of Health and Population, Population Division. Nepal Population Report 2011, Ramshahpath, Kathmandu: Ministry of Health and Population.

7. Kathleen M. Kurz. Adolescent Nutritional Status in Developing Countries, International Center for Research on Women, 1717 Massachusetts Avenue, NW, Washington, DC20036, USA
8. Regmi, S., Adhikari, R.. A Study on the Factors Influencing Nutritional Status of Adolescent Girls in Nepal. Nutrition of Adolescent Girls Research Program no. 6. 1994. Washington, DC: International Center for Research on Women.

9. Nitish Mondal, Jaydip Sen.Prevalence of Stunting and Thinness Among Rural Adolescents of Darjeeling district, West Bengal, India. Italian Journal of Public Health, 2010, Volume 7, Number 1

10. Das DK, Biswas R. Nutritional Status of Adolescent Girls in a Rural Area of North 24 Paraganus Ddistrict, West Bengal. Indian J Pub Health.2005; 49(1):18-21.

11. TolessaDekebaDamie, Mektie Wondafrash, Aderajew Nigussie. Nutritional Status and Associated Factors Among School Adolescent in Chiro Town, Westhararge, Ethiopia. Gaziantep Med J 2015;21(1):32-42

12. ElhamKavosi, Zahra HassanzadehRostami, Zahra Kavosi, Aliasghar Nasihatkon, Mohsen Moghadami, et.al.. Prevalence and determinants of under-nutrition among children under six: a cross-sectional survey in Fars province, Iran. Int J Health Policy Manag 2014, 3(2), 71-76. 